\title{
DO CORPO ÀS EMOÇÕES: O ROSTO DE MARIELLE RESSIGNIFICANDO O MEDO
}

Elizete Bernardes (IFMS) - elizete.bernardes@ifms.edu.br

Solange Christiane Gonzalez Barros (Rede Estadual de Ed. de SP) solcgbarros@yahoo.com.br

RESUMO: Neste artigo, a partir das contribuições da Análise de discurso (AD) bem como da Semiologia Histórica (COURTINE, 1988; 2015), propomos algumas análises iniciais entre a emoção, o corpo e como o discurso enlaça os dois primeiros elementos. Assim, nosso questionamento de escrita é: como o medo pode ser instalado como uma estratégia de governo biopolítico direcionado para corpos de determinados sujeitos? Nesse sentido, consideramos alguns enunciados (verbais e não verbais) que circularam na mídia durante as vésperas e póseleições presidenciais de 2018. Tomamos como hipótese de reflexão, ressignificando Pêcheux (2009), que as emoções podem mudar de sentido conforme o corpo do sujeito que as suscita. De modo que, nosso objetivo é a articular os sentidos que se constroem a partir do corpo e da emoção de diferentes sujeitos. Para tanto, analisamos como o rosto de Marielle Franco, após seu assassinato, e o medo elou ansiedade suscitados com este acontecimento discursivo se ressignifica dentro da fragilidade da democracia. Esperamos, ao final, contribuir para os estudos do discurso bem como demonstrar como a necropolítica (MBEMBE, 2018) está implicada em emoções que atravessam os corpos.

Palavras-chave: Análise do discurso; corpo; emoções; medo; necropolítica.

ABSTRACT: In this article, concerning the point of view of French Discourse Analysis (AD) approach as well as Historical Semiology (COURTINE, 1988; 2015), we propose some initial analyzes between emotion, body and how the discourse links the first two elements. Thus, the question that instigate us to think is: how can fear be installed as a biopolitical government strategy directed towards the bodies of certain subjects? In this sense, we consider some utterances (verbal and non-verbal) that circulated in the media during presidential evees and post-elections in 2018. Our hypothesis of reflection, re-establishing Pêcheux (2009), that emotions can change meaning according to body of the subject that arouses them. So, our goal is to articulate the meanings that are built from the body and the emotion of different subjects. In order to do so, we analyze how the face of Marielle Franco, after his assassination, and the fear and anxiety aroused by this discursive event is re-established within the fragility of democracy. In the end, we intend to contribute to discourse studies as well as to demonstrate how biopolitics is implicated in emotions that run through bodies.

Keywords: Discourse Analysis; body; emotions; fear; biopolitics. 


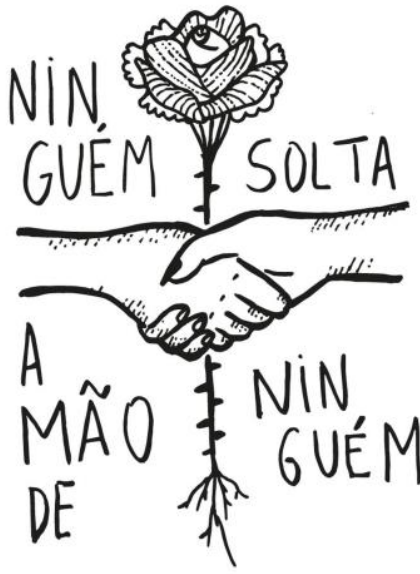

CONSIDERAÇÕES INICIAIS

Quem foi de aço nos anos de chumbo

Brasil, chegou a vez

De ouvir as Marias, Mahins, Marielles, malês ${ }^{1}$

G.R.E.S. Estação Primeira de Mangueira (2019).

Figura 1 - Enunciado em acontecimento

A noite do dia 28 de outubro de 2018 só anunciava um acontecimento: Jair Bolsonaro é o presidente eleito do Brasil. Entre buzinaços, rojões e gritos de euforia vindos de fora da janela, recebemos, via Whatsapp, a seguinte postagem: "ninguém solta a mão de ninguém” (Figura 1). A circulação da publicação, de autoria da tatuadora e artista Thereza Nardelli, não tardou a viralizar nas redes sociais. Naquele momento, o enunciado materializava um sentimento experimentado durante toda a corrida eleitoral: o medo, ou antes, o medo de ter medo. Agora, o medo sufocava diversos sujeitos. O medo não era individual, era partilhado por muitos. Mas, muitos, quem?

O acontecimento discursivo se instaurava aí: "ninguém solta a mão de ninguém" acionava a memória discursiva de outra época, os Anos de Chumbo. Neste período, segundo o Jornal GGN, quando as luzes se apagavam repentinamente nos barracos onde funcionavam o Curso de Ciências Sociais da USP, os estudantes buscavam as mãos uns dos outros para se acolherem, se protegerem, resistirem e, quem sabe, re-existirem à truculência da ditadura. Ao meio dessa violência, eles gritavam: "ninguém solta a mão de ninguém".

\footnotetext{
1 "Histórias para ninar gente grande": este é o samba-enredo do Grêmio Recreativo Escola de Samba (G.R.E.S) da Estação Primeira de Mangueira, vencedor dos desfiles das escolas de samba do Rio de Janeiro, em 2019.
} 


\section{Ñanduty}

Em 2018, o mesmo enunciado é reativado, guardando algumas continuidades com aquele período, mas, sobretudo, atualizando novos efeitos de sentidos. Para além do enunciado verbal e linguisticamente marcado, havia uma (des)continuidade na emoção partilhada por aqueles que se davam as mãos. Em outros termos, a memória de acontecimentos de outros períodos de nossa história aciona certas emoções em determinados sujeitos. Para essa escrita, as emoções consideradas circulam entre o medo e o medo de ter medo que tomou conta de nossos corpos, enquanto sujeitos.

Na corrida presidencial de 2018, a emoção que tomou conta de nós era o medo de ter medo: a ansiedade. Assim, o discurso, ao entrelaçar a história e os dois acontecimentos, fazia emergir emoções antigas e atualizava novas emoções. Afinal, como nos explica Courtine (2015: 24): "o medo possui um objeto preciso; no medo, sabemos o que nos ameaça, enquanto a ansiedade não, ou, antes, a ansiedade possui um tal objeto, mas se trata de um objeto que não conhecemos". Se preferirem, nas palavras de Bauman:

O medo é mais assustador quando difuso, disperso, indistinto, desvinculado, desancorado, flutuante, sem endereço, nem motivo claros; quando nos assombra sem que haja uma explicação visível, quando a ameaça que devemos temer pode ser vislumbrada em toda parte, mas em qualquer lugar se pode vê-la. "Medo" é o nome que damos a nossa incerteza: nossa ignorância da ameaça e do que deve ser feito - do que pode e do que não pode - para fazê-la parar ou enfrentá-la, se cessá-la estiver além do nosso alcance. (BAUMAN, 2008: 8).

De modo que o questionamento de escrita é refletir como a ansiedade e o medo foram discursivizados como uma forma de governo biopolítico a partir dos corpos de determinados sujeitos durante as vésperas e pós-eleições presidenciais de 2018. Para tanto, tomamos como objetivo de escrita a articulação entre o os sentidos que se construíram a partir do rosto de Marielle Franco, após seu assassinato, e o medo elou ansiedade suscitados com este acontecimento discursivo que, constantemente, se ressignifica.

Ao final do texto, portanto, sob o prisma dos estudos do discurso, pretendemos analisar como corpos de certos sujeitos podem deslocar as emoções conforme a posição de sujeito determinada por aqueles que os olham, reapropriando-me dos ensinamentos 


\section{Nanduty}

ISSN:2317-8590

de Pêcheux (2009: 146-147)². Para tanto, neste artigo, iremos nos centrar na questão do corpo da mulher negra ${ }^{3}$.

\section{QUEM, AFINAL, TEM MEDO?}

Do primeiro turno das eleições presidenciais ao segundo, dia 28 de outubro, muitos discursos, emoções (inflamadas) e corpos circularam nas ruas, nas redes sociais, nos noticiários, etc. Eleições marcadas pela polarização: direita e esquerda, coxinhas e petralhas, liberais e comunistas, entre tantos adjetivos para qualificar os sujeitos de acordo com seu posicionamento político. As emoções à flor da pele pendiam tanto para um lado quanto para o outro.

Assim, em breve pesquisa pelo Google, alguns títulos dos gêneros discursivos da esfera jornalística alertavam: "Eleições 2018: como se proteger da tristeza, da raiva e do medo?"; "As eleições do desencanto e do medo"; "A verdadeira pauta das eleições 2018 é o medo"; “ 'Eleição tem sido dominada por medo e raiva', diz psicólogo”; “ 'O medo vai ter um peso enorme na eleição 2018', diz jornalista"; etc. O medo, portanto, além de ser o denominador comum das emoções eleitorais 2018, parecia ser um instrumento de governo, cujos poderes se exerceriam sobre o corpo-indivíduo (como por exemplo, o exílio do deputado Jean Wyllys, motivado pelo medo) mas, sobretudo, sobre o corpopopulação, conforme nos instigou a matéria: "No interior do Nordeste, candidatos apelam ao medo para conquistar votos".

Havia, dessa maneira, de um lado, desde o medo em adesivar o seu carro com a cor vermelha, perpassando o medo da volta ao regime ditatorial até o medo de sair às ruas, corroborados por discursos de ódio que endossavam violências físicas e simbólicas. Do lado de lá, dizia-se sobre o medo pela implantação do comunismo, em transformar o Brasil numa Venezuela, o medo da destruição da "família tradicional

\footnotetext{
${ }^{2}$ Em Semântica e Discurso (2009, p. 146-147), Michel Pêcheux nos diz: "as palavras, expressões, proposições etc., mudam de sentido segundo as posições sustentadas por aqueles que as empregam".

${ }^{3}$ Este artigo é parte de algumas reflexões levantadas durante os encontros com o grupo de pesquisa "Discurso, Memória e Violência" (CNPq: http://dgp.cnpq.br/dgp/espelhorh/1471567021751171), coordenado pelo professor doutor Marcos Lúcio de Sousa Góis, da Universidade Federal da Grande Dourados (UFGD).
} 


\section{Nanduty}

ISSN:2317-8590

brasileira" (ameaçada por corpos LGBTQ+), o medo da desconhecida "ideologia de gênero" (materializada na famigerada fake news do "Kit Gay"), etc.

Vale ressaltar que, ainda que o recenseamento sobre os medos que assombra(va)m a população neste período eleitoral seja extenso, plural e também marcado por posições político-ideológicas, neste artigo iremos nos centrar em alguns medos de determinados sujeitos ou grupos minoritários, a saber: da população negra.

Tanto o medo do já posto, do objeto preciso, na instância do já-lá, quanto o medo do por-vir, do quase-lá tomava conta do quadro político, do governo dos indivíduos e da coletividade, da disciplina ao biopoder. Em síntese, as emoções que atravessaram os discursos às vésperas das eleições presidenciais não eram individuais, mas sim compartilhados por muitos sujeitos e esse caráter coletivo que produz os laços entre as emoções e o discurso, conforme destaca Courtine (2016), possuem

alguns traços discursivos recorrentes: sua permanência, pois ela não conhece nenhuma interrupção; sua onipresença, da qual deriva o fato de que as ameaças globais andam lado a lado com as preocupações locais; sua intensidade variável, quando os grandes perigos alternam-se com inquietudes menores; sua indiferença para com a realidade dos perigos, quando nada mais distingue as catástrofes reais das puras construções imaginárias [...]; seu caráter cumulativo, como se a adição das ameaças, a soma dos medos ou a multiplicidade de seus objetos [...] constituíssem a prova de sua existência; sua relação particular com o tempo: o presente dos medos contemporâneos é assombrado pela evocação de medos antigos [...]. Em suma, é a confusão dos tempos, dos lugares, dos objetos, dos perigos imaginários e dos riscos reais que impera nos discursos em que se materializam os medos contemporâneos. (COURTINE, 2016: 21). (grifo nosso).

Considerando as observações midiático-jornalísticas, bem como o caráter particular com o tempo, propomos a reflexão de como as emoções estão diretamente implicadas nos discursos. Em outras palavras, uma vez que os discursos são práticas assinaladas sócio-historicamente por sujeitos e materializadas linguisticamente, não podemos deixar calar o pathos que move esses dizeres em curso. Por essa razão, busco localizar as sensibilidades que afetam os discursos, pois, hipoteticamente, as emoções podem sofrer um deslizamento semântico conforme as posições ocupadas historicamente pelos sujeitos-corpos envolvidos (sujeito que olha e o sujeito que é olhado) no processo da construção dos sentidos. 


\section{Nanduty}

Um corpo indígena pode inflamar emoções diferentes em determinados sujeitos, desde compaixão até massacres invisibilizados pela mídia. Da mesma forma, um corpo LGBTQ+ suscita diversas reações e é visto como ameaças contra outros sujeitos ou vistos como corpos livres e identitários. Os nordestinos, as comunidades quilombolas e mulheres negras, enquanto um corpo social e coletivo, podem se tornar objetos de incitação ao ódio ou suscitação à empatia, a depender o lugar ocupado pelo sujeito no discurso.

Embora nosso prisma de escrita e reflexão seja de cunho discursivo, parece-me que a elasticidade de um extremo ao outro, do ódio à empatia, não é tão polarizada assim. Parece-me, antes, que a relação entre a emoção e o discurso se aproxima muito mais do movimento de um pêndulo, em que, de um ponto ao outro, do ódio à civilidade, iremos transitar por outros fatores - não só político-ideológicos -, mas também pessoais, econômicos, de gênero, étnico-raciais, as próprias condições históricas do acontecimento em questão, etc.

Assim, nessa linha elástica entre o ódio e o amor, a matéria jornalística denunciava: "Gays, negros e indígenas já sentem nas ruas o medo de um governo Bolsonaro". Discursivamente, todos esses sujeitos-corpos estão assinalados na história, no tempo e nos lugares. Quais medos esses corpos (re)apresentam? Como certas memórias (e não outras em seu lugar) são reativadas ao estarem diante desses corpos? Quem são os bárbaros e quem são os civilizados?

\section{A ORDEM DO OLHAR DOS BÁRBAROS, DO ÓDIO À CIVILIDADE}

Em sua obra $O$ medo dos bárbaros (2010), Tzvetan Todorov nos instiga a problematizar como o medo dolao Outro pode nos aproximar da barbárie e, consequentemente, distanciando-nos dos valores da civilidade. Para tanto, o filósofo provoca:

[...] Os bárbaros são aqueles que, em vez de reconhecerem os outros como seres humanos semelhantes a eles, acabam por considerá-los como assimiláveis aos animais, ao consumi-los ou ao julgá-los incapazes de refletir e, portanto, de 


\section{Nanduty}

negociar, indignos de viver em liberdade; eles limitam-se a conviver com os parentes de sangue e ignoram a vida social regida por leis comuns. [...]

Os bárbaros são aqueles que negam a plena humanidade dos outros: em vez de significar que eles ignoram ou esquecem, realmente, a natureza humana dos outros, eles comportam-se como se os outros não fossem - ou, de qualquer modo, não inteiramente - seres humanos. (TODOROV, 2010: 26-27).

Em Bernardes (2017; 2018), foram realizadas algumas reflexões sobre o corpo no Direito. Nestes textos, a autora apresenta como o discurso é o laço que une o corpo à pessoa. Entre tantas figuras jurídicas que limitam o pleno exercício das garantias fundamentais do corpo-pessoa, temos a liberdade de ir e vir (Art. 5º, XV, da Constituição Federal). Nesta conjuntura em que o medo é a emoção que toma conta de nossos corpos, esse direito individual - que não deixa de ser coletivo - torna-se ameaçado, conforme vimos em alguns títulos de matérias jornalísticas na seção anterior.

Com efeito, Bauman (2008) afirma que os perigos que nos causam medo são de três tipos:

\footnotetext{
Alguns ameaçam o corpo e as propriedades. Outros são de natureza mais geral, ameaçando a durabilidade da ordem social e a confiabilidade nela, da qual depende a segurança do sustento (renda, emprego) ou mesmo da sobrevivência no caso de invalidez ou velhice. Depois vêm os perigos que ameaçam o lugar da pessoa no mundo - a posição na hierarquia social, a identidade (de classe, de gênero, étnica, religiosa) e de modo mais geral à degradação e à exclusão sociais. (BAUMAN, 2008: 10).
}

Assim, a próxima seção será dedicada a pensar o medo materializado num corpo de um sujeito e seu lugar ocupado no discurso. Quais os perigos de um corpo feminino, negro, lésbico, periférico que ameaçam certos lugares e hierarquias sociais e identitárias?

\section{O MEDO DO FUTURO REPETIR O PASSADO}

Neste momento, três imagens servirão como fio condutor para empreendermos nossas análises entre corpo, medo e discurso. As três figuras referem-se à vereadora carioca Marielle Franco, executada brutalmente, ao lado de seu motorista Anderson, em março de 2018. Sem esquecermos nossa veia discursiva, é importante lembrar que, em nossa reflexão, emerge o sujeito, ou seja, o indivíduo Marielle Franco deixa espaço para 


\section{Nanduty}

ISSN:2317-8590

que o sujeito político-ideológico venha ocupar um lugar no discurso e é a partir desse lugar que nossa reflexão e escrita se situam. Esse espaço se circunscreve a partir de suas posições político-ideológicas: enquanto mulher e feminista, negra, lésbica, moradora da favela carioca e parlamentar, Marielle Franco lutava a favor dos direitos humanos, de causas minoritárias e da comunidade LGBT, entre outras questões igualmente importantes.

O primeiro grafite (Figura 2) foi feito em São Paulo e trazia o rosto de Marielle e todos os sinais que a identificavam dentro de um campo semântico, quais sejam, os seus traços negroides (pele negra, lábios grossos, cabelo crespo e solto, nariz largo, etc.) Ao lado do não verbal, foi inscrito no painel alguns enunciados que exaltavam a sua figura, dentre os quais: "Marielle Presente". Em maio de 2018, entretanto, o painel foi alvo de vandalismo e tintas (pretas e vermelhas) foram derramadas sobre a representação do rosto de Marielle. Além disso, os enunciados verbais foram apagados com tinta branca. De "Marielle Presente" para Marielle Ausente.

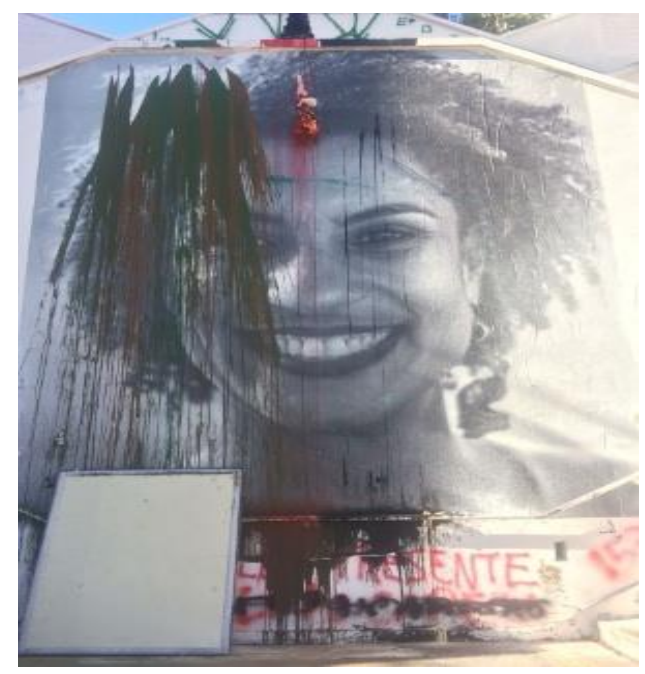

Figura 2 - Corpo pichado, memória apagada? ${ }^{4}$

Em termos discursivos, não se trata apenas de um ato ilegal, passível de punição, mas, de sobremaneira, temos um movimento de memória e esquecimento. Num

\footnotetext{
${ }^{4}$ Imagem extraída do sítio: https://noticias.uol.com.br/cotidiano/ultimas-noticias/2018/05/27/viuva-demarielle-se-oferece-para-reconstituir-painel-depredado-em-sp-nao-vao-silencia-la.htm. (acessado em 15 de janeiro de 2019).
} 


\section{Nanduty}

ISSN:2317-8590

primeiro momento, chamamos de memória lembrada (quando se pinta o seu rosto num local público) e, num segundo momento, com a depredação, consideramos que há um gesto de tentativa de apagamento dessa memória. O corpo do sujeito que ali se instaura, para depois ser apagado e, finalmente, ser restaurado ${ }^{5}$ entra em embate na arena dos discursos. Afinal, como nos ensinou Foucault (2013), o corpo é político, uma vez que, "está diretamente mergulhado num campo político; as relações de poder têm alcance imediato sobre ele; elas o investem, o marcam, o dirigem, o suplicam, sujeitam-no a trabalhos, obrigam-no a cerimônias, exigem-lhe sinais". (FOUCAULT, 2014: 29).

O segundo grafite (Figura 3), feito em julho pela ganhadora do Nobel da Paz de 2014, Malala Yousafzai, agora no Rio de Janeiro, a partir da técnica chamada stencil, é outro exemplo de memória que se quer silenciar com o apagamento do rosto. $\mathrm{Na}$ pintura, além da fisionomia de Marielle (com todos os seus traços e significação), outro rosto muito conhecido por nós, da ativista Maria da Penha, é pichado.

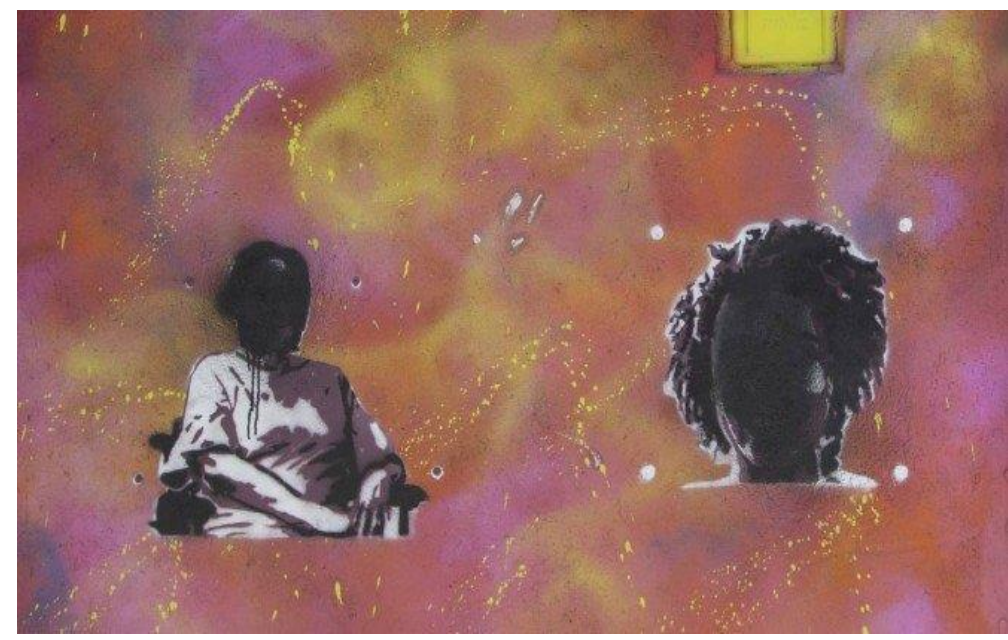

Figura 3 - Rostos apagados, memória silenciada? ${ }^{6}$

Ao contrário da pichação na totalidade do stencil de Marielle, com o grafite de Maria da Penha o que vemos é um apagamento de seu rosto, preservando o seu corpo

\footnotetext{
5 O painel foi restaurado em julho do mesmo ano. Agora, com alguns outros enunciados verbais: "Vai ter luta", "Não serei interrompida".

6 Foto de Márcia Foletto para a Agência $O$ Globo. In: https://oglobo.globo.com/rio/camera-flagrahomem-vandalizando-grafite-com-rosto-de-marielle-maria-da-penha-veja-video-23315720. (acessado em 15 de janeiro de 2019).
} 


\section{Ñanduty}

ISSN:2317-8590

paraplégico na cadeira de rodas. Um dos efeitos de sentidos possível é pensar que o corpo deficiente é digno de reconhecimento em sua humanidade, e não deve ser apagado. Entretanto, ao se apagar o rosto daquele corpo, da Maria da Penha, o gesto significa na medida em que é pelo seu rosto que se identifica o seu ativismo social e político no combate à violência doméstica que, infelizmente, acarretou a sua paraplegia. Assim, nesse desenho, temos metade de uma memória que deve ser lembrada (os corpos deficientes) e, de outro, uma memória que deve ser apagada (o rosto de Penha e sua identificação política).

Em síntese, há duas mulheres e as violências que se inscreve(ra)m sob a superfície de seus corpos: uma executada e a outra, vítima da violência doméstica. Elas, vítimas do não reconhecimento de sua plena humanidade. Seus rostos pichados, uma reverberação das violências simbólicas a que estes sujeitos também estão submetidos em nossa sociedade. Em última instância, trata-se da confirmação do não reconhecimento da humanidade desses dois sujeitos históricos e coletivos (mulheres, negras, lésbicas, etc.) enredados em dois corpos e seus signos. Ou seja, o rosto de Marielle recoberto pelo discurso e pela história dos signos que o marcam. Nesse sentido, a História do Rosto (COURTINE, 1988) nos ensina que é o discurso que costura a fisionomia com a semiologia do corpo de Marielle:

Uma semiologia da superfície corporal: indica os sinais comuns e derivados, ensina a localizá-los, a hierarquizá-los, a relacioná-los uns com os outros no termo de um cálculo. Corpo e rosto são recobertos pouco a pouco pela rede de um discurso que estabelece a ligação entre a aparência e a interioridade. [...] o discurso tende a ordená-los numa lista hierarquizada de órgãos de indícios que traduzem e comandam o percurso do olhar sobre o corpo visível. [...] Como se lentamente se interpusesse entre o rosto e o olhar que o observa o véu silencioso e quase transparente da linguagem. (COURTINE, 1988: 56).

Por fim, a Figura 4, abaixo, é uma fotografia cujo exercício de poder segue a mesma linha das outras duas imagens: apagamento de uma memória com a quebra de um corpo. Na ocasião, em outubro de 2018, ou seja, vésperas das eleições, o deputado Rodrigo Amorim divulga em suas redes sociais o seguinte registro: 


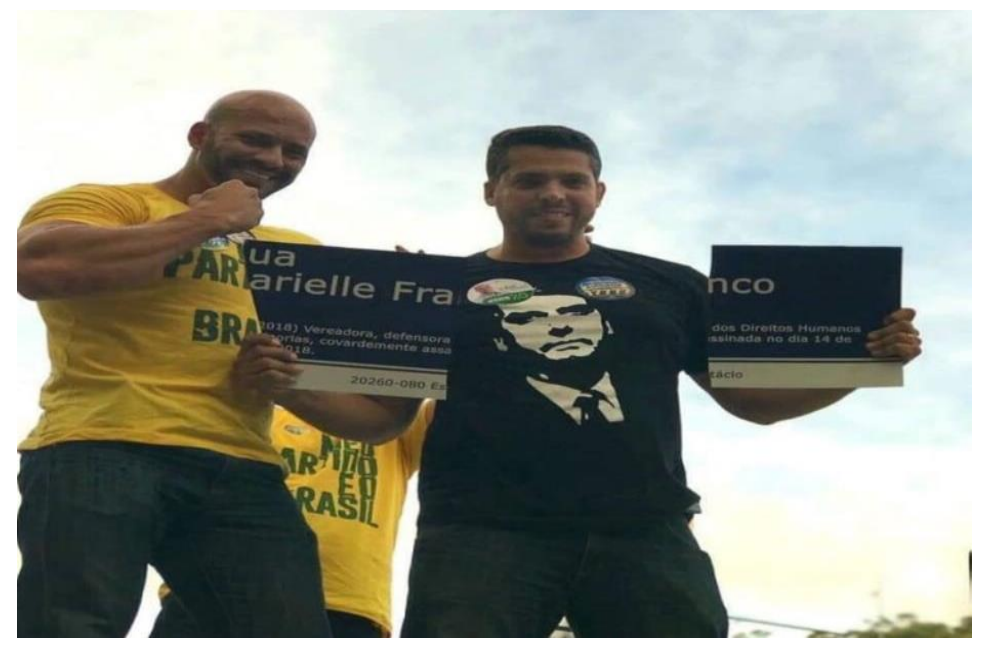

Figura 4 - Memória quebrada ${ }^{7}$

$\mathrm{Na}$ fotografia (Figura 4), vemos três homens, dois dos quais vestem camisetas verde-e-amarela, estampando em seus peitos: "Meu partido é o Brasil". Ao lado deles, há o candidato a deputado estadual do partido do então presidenciável Jair Bolsonaro (PSL), cujo rosto está estampado na camiseta de Amorim. Nas mãos deste, a placa com a inscrição "Rua Marielle Franco" está quebrada. O gesto é celebrado com sorrisos e com força: ambos sujeitos estampam um sorriso de satisfação e músculos contraídos. O indivíduo de verde-e-amarelo cerra os punhos, levanta o braço na altura de seu queixo e contrai os músculos, um gesto bastante significativo no âmbito da comemoração de uma vitória. O outro sujeito, Amorim, com Bolsonaro em seu peito aberto, segura a materialização de seu ato heroico: a memória quebrada.

Levando em consideração as discussões do antropólogo Arjun Appadurai (2009), a Figura 4 nos remete à questão de identidades predatórias, concebidas como identidades de mobilização e construção social com vistas à extinção de outras categorias sociais próximas. Neste caso, estabelecemos uma relação entre membros predatórios (mobilização dos homens) e a parte que deve ser extinta (a mulher negra, politizada, representante de uma minoria), acarretando na transformação de uma identidade social benigna numa identidade predatória.

\footnotetext{
7 Imagem retirada do Instagram. In: https://politica.estadao.com.br/noticias/eleicoes,candidatos-do-psldestroem-placa-com-homenagem-a-marielle-franco,70002531740. (acessado em 15 de janeiro de 2019).
} 


\section{Nanduty}

O enunciado verbal que sincreticamente produz significados ao lado da fotografia publicada nas redes sociais do candidato dizia:

Depredação do patrimônio público [...] removeram ilegalmente a placa com o nome original, colando uma placa fake (falsa) com os dizeres 'Rua Marielle Franco' em cima da placa original. Cumprindo nosso dever cívico, removemos a depredação e restauramos a placa em homenagem ao grande marechal. Preparem-se, esquerdopatas: no que depender de nós, seus dias estão contados. (AMORIM, 2018)

Longe de ser uma mobilização bem sucedida, a legenda da fotografia (Figura 4) ironiza o fato de se ter posto uma placa com os dizeres "Rua: Marielle Franco" no lugar da placa anterior ("Praça Marechal Floriano"). Em tom de deboche, e a serviço de um "dever cívico", observamos que o sujeito põe em circulação um embate discursivo já estabelecido - especialmente durante a corrida eleitoral presidencial. Em outros termos, são memórias discursivas que entram em conflito: de um lado, "Marechal Floriano" aciona a memória de um militar na política (ou melhor, o "Marechal de Ferro" de Euclides da Cunha9), por consequência, lembrando-nos da truculência de períodos ditatoriais de nossa história. De outra banda, a memória que se pretendia sobrepor àquela, a "Rua Marielle Franco", disputa um espaço simbólico a fim de que todos os significados deste corpo-sujeito se (re)produzam em espaços públicos e físicos. Na rua e na praça teremos mulheres, negras, gays, faveladas e parlamentares; ou seja, de acordo com Appadurai (2009) são pequenos números que constituem um ruído, perturbação, ares de traição.

Temos aí, portanto, o embate de memórias que se pretendem presentes, e mais: uma vez presente, que se ausente a outra memória. Nesse sentido, conforme ZoppiFontana (2011) nos instiga a refletir sobre as (in)visibilidades e a construção das

\footnotetext{
${ }^{8}$ Imagem retirada do Instagram. In: https://politica.estadao.com.br/noticias/eleicoes,candidatos-do-psldestroem-placa-com-homenagem-a-marielle-franco,70002531740. (acessado em 15 de janeiro de 2019).

9 "O Marechal de Floriano Peixoto destacou-se pelo contraste. Ele foi calmo, prudente e cético entre pessoas entusiastas, ardentes e apaixonadas. Foi um herói excêntrico. Representou nossa fraqueza, ao invés de nossa força. Ele cresceu ao mesmo tempo em que a energia nacional diminuía. [...]" (CUNHA, 1997, p. 92).
} 


\section{Ñanduty}

ISSN:2317-8590

democracias, há "duas formas de presença, no batimento presençalausência, tais como elas circulam na mídia: a imagem de X que circula para tornar invisível a imagem de $Y$ [...], as substituições, os apagamentos, as sombras, os espectros”. (idem, p. 178).

O medo ganha corpo nessas imagens (Figuras 2, 3 e 4). Corporificado numa mulher, negra, moradora da favela, lésbica, o medo conjuga nesse corpo as medidas entre a civilidade e a barbárie, entre a empatia e o ódio, entre o reconhecimento do seu caráter humano e a sua completa anulação. O medo, materializado na violência simbólica desses atos de depredação, nos diz: não basta que o corpo já esteja morto e enterrado, é preciso que seus signos sejam apagados, pichados e destruídos; não basta que o corpo, submetido a uma violência física brutal inscrita em sua superfície, tenha sido assassinado, é necessário ainda que o sujeito prove sua inocência. O corpo morto não é suficiente para enterrar uma memória.

\section{A BIOPOLÍTICA E O MEDO DO ESTADO RACISTA}

Neste tópico, procuraremos fechar nossa linha de argumentação, enlaçando o medo ou o medo de morrer com os mecanismos de exercícios de poderes direcionados a certos corpos. Para tanto, consideraremos a Aula de 17 de março de 1976, ministrada pelo filósofo Michel Foucault, Em defesa da Sociedade (1999), nas questões pertinentes ao racismo enquanto vetor para incutir técnicas de poder de "deixar morrer".

Com efeito, se no poder disciplinar, os exercícios de poderes são dirigidos ao corpo-indivíduo, na biopolítica, as técnicas de regulamentação da vida se darão em nível do corpo-população, tornando os corpos dóceis, úteis e produtivos. Disciplina e biopolítica como séries não excludentes, mas, de sobremaneira, complementares. Entretanto, o filósofo francês nos instiga a pensar no seguinte contraponto da bioregulamentação: "Como um poder como este pode matar, se é verdade que se trata essencialmente de aumentar a vida, de prolongar sua duração, de multiplicar suas possibilidades, de desviar seus acidentes, ou então de compensar suas deficiências?" (FOUCAULT, 1999: 304). E sentenciará: o racismo foi inserido nas técnicas do Estado de regulamentação da vida no momento da emergência do biopoder. 


\section{Nanduty}

[...] que é o racismo? É, primeiro, o meio de introduzir afinal, neste domínio da vida de que o poder se incumbiu, um corte: o corte entre o que deve viver e o que deve morrer. [...].

De outro lado, $[. .$.$] o racismo vai permitir estabelecer, entre a minha vida e a$ morte do outro, uma relação que não é uma relação militar e guerreira de enfrentamento, mas uma relação do tipo biológico: "quanto mais as espécies inferiores tenderem a desaparecer, menos degenerados haverá em relação à espécie" [...]. A morte do outro não é simplesmente a minha vida, na medida que seria minha segurança pessoal; a morte do outro, da raça ruim, da raça inferior (ou do degenerado, ou do anormal), é o que vai deixar a vida em geral mais sadia; mais sadia e mais pura. [...].

A raça, o racismo é a condição de aceitabilidade de tirar a vida numa sociedade de normalização. (FOUCAULT, 1999: 304-306).

Em outros termos, a necropolítica, conforme ensaia Achilles Mbembe (2018), pressupõe que "a expressão máxima da soberania reside, em grande medida, no poder e na capacidade de ditar quem pode viver e quem deve morrer. [...]. Ser soberano é exercer controle sobre a mortalidade e definir a vida como a implantação e manifestação de poder". (idem, p. 05).

De modo que, o rosto e o corpo de Marielle, ao carregar os signos e sinais da raça negra, materializam práticas violentas e historicamente marcadas pelo racismo. "Que lugar é dado à vida, à morte e ao corpo humano (em especial o corpo ferido ou massacrado)? Como eles estão inscritos na ordem do poder?” (MBEMBE, 2018, p. 7). Um corpo-indivíduo que se pulveriza e se ressignifica em seus traços biológicos e fenotípicos num corpo-população negra. Esta, por sua vez, compartilha do medo de ser o potencial corpo-alvo de técnicas e mecanismos de "deixar morrer"; de práticas higienistas; de corpos submetidos a uma seleção "natural" e evolucionista de um discurso político que legitima o racismo e a própria "condição de se exercer o direito de matar" (FOUCAULT, 1999: 306).

\section{CONSIDERAÇÕES FINAIS}

$\mathrm{O}$ rosto e corpo de Marielle entram em acontecimento discursivo, uma vez que o velho se atualiza no novo. A novidade que se instaura não se restringe apenas ao fato de seu rosto ser quase anônimo até sua morte, mas, de sobremaneira, porque os sentidos que vão se construindo desde o evento se atualizam constantemente, seja pelos 


\section{Nanduty}

ISSN:2317-8590

discursos, seja pelas emoções que o atravessam. A tentativa do majoritarianismo a fim de garantir a extinção de uma minoria ameaçadora à sua sobrevivência, por fím, acarretou no fortalecimento desta coletividade representada por Marielle.

O medo ou o medo de ter medo se constroem como uma emoção coletiva, conforme ressalta Courtine (2016), mas esta sensibilidade se inscreve numa história dos corpos: as legibilidades destes enlaçam as emoções de lá e de cá, do passado e do presente.

\section{REFERÊNCIAS BIBLIOGRÁFICAS}

APPADURAI, A. O medo ao pequeno número: Ensaio sobre a geografia da raiva. São Paulo: Iluminuras: Itaú Cultural, 2009.

ARIAS, Juan. 2018. As eleições do desencanto $e$ do medo. In: https://brasil.elpais.com/brasil/2018/08/15/opinion/1534335413_493427.html.

(acessado em 14 de janeiro de 2019).

AZEVEDO, Luiz Carlos. 2018. O medo vai ter um peso enorme nas eleições 2018. In: https://www.gazetaonline.com.br/noticias/politica/2017/11/o-medo-vai-ter-um-pesoenorme-na-eleicao-de-2018--diz-jornalista-1014108692.html. (acessado em 14 de janeiro de 2019).

BARROS, Carlos Juliano. 2018. Com medo de ameaças, Jean Wyllys, do PSOL, desiste de mandato e deixa o Brasil. In: https://www1.folha.uol.com.br/poder/2019/01/commedo-de-ameacas-jean-wyllys-do-psol-desiste-de-mandato-e-deixa-o-brasil.shtml. (acessado em 19 de fevereiro de 2018).

BAUMAN, Zygmunt. Medo líquido. Trad. Carlos Alberto Medeiros. Rio de Janeiro: Zahar, 2008.

BERNARDES, Elizete de Souza; SARGENTINI, Vanice de Oliveira. 2018. "De um gesto nem tão livre quanto obsceno: alguns limites do direito de dispor de si". In: SOARES, Thiago Barbosa. (org.). Múltiplas perspectivas em Análise do discurso: objetos variados. São Carlos, Pedro \& João Editores, p. 9-28.

2017. "O corpo no Arquivo Jurídico: uma análise discursiva sobre a prostituta". Revista MOARA: Estudos linguísticos. 47: 213-232.

BRASIL. Constituição da República Federativa do Brasil [1988]. 2011. Vade Mecum: obra coletiva de autoria da Editora Saraiva com a colaboração de Antonio Luiz de Toledo Pinto, Márcia Cristina Vaz dos Santos Windt e Livia Céspede. $11^{\mathrm{a}}$ ed. São Paulo, Saraiva.

CARVALHO, Letícia. 2018. "Eleição tem sido dominada por medo e raiva", diz psicólogo; leia entrevista. In: https://g1.globo.com/df/distritofederal/noticia/2018/10/14/eleicao-tem-sido-dominada-por-medo-e-raiva-diz-psicologoleia-entrevista.ghtml. (acessado em 14 de janeiro de 2019). 


\section{Nanduty}

ISSN:2317-8590

COURTINE, J.J. 2016. "A era da ansiedade: discursos, história e emoções". In.: PIOVEZANI, Carlos (org). (In)subordinações contemporâneas: consensos $e$ resistências nos discursos. São Carlos, EdUFSCar, p. 15-29.

1988. História do rosto: exprimir e calar as suas emoções (do século XVI ao início do século XIX). Trad. Ana Moura. Editorial Teorema, Lisboa.

CUNHA, Euclides da. 1997. "O Marechal de Ferro". Revista Parcerias estratégicas. Brasília, 4(1): 89-92.

FOUCAULT, Michel. 2014. Vigiar e punir: nascimento da prisão. 42a ed. Tradução de Raquel Ramalhete. Petrópolis: Vozes. 1999. Em defesa da sociedade: curso no Collège de France (1975-1976).

Aula de 17 de março de 1976. Tradução de Maria Emantina Galvão. São Paulo: Martins Fontes.

GAMA, Alyne; MADEIRO, Carlos .2018. No interior do Nordeste, candidatos apelam ao medo para conquistar votos. https://noticias.uol.com.br/politica/eleicoes/2018/noticias/2018/10/21/voto-do-interiordo-nordeste-se-baseia-em-medos-e-desinformacao.htm. (acessado em 14 de janeiro de 2019).

MBEMBE, Achille. Necropolítica: biopoder, soberania, estado de exceção, política da morte. Trad. Renata Santini. São Paulo: n-1 edições, 2018.

NASSI, Luis. A origem do "ninguém solta a mão de ninguém". Jornal GGN. Cultura. In: https://jornalggn.com.br/noticia/a-origem-do-ninguem-solta-a-mao-de-ninguem-pormarcelo-mendonca (acessado em 27 dezembro de 2018).

OLIVEIRA, Joana. Gays, negros e indígenas já sentem nas ruas o medo de um governo Bolsonaro.

In: https://brasil.elpais.com/brasil/2018/10/18/politica/1539891924_366363.html. (acessado em 14 de janeiro de 2019).

PÊCHEUX, Michel. 2009. Semântica e Discurso: uma crítica à afirmação do óbvio. $4^{\mathrm{a}}$ ed. Tradução de Eni Puccinelli Orlandi. Campinas, Editora da Unicamp.

ROESLER, Átila da Rold. 2018. A verdadeira pauta das eleições 2018 é o medo. Justificando: mentes inquietas pensam Direito. In: http://www.justificando.com/2018/08/29/a-verdadeira-pauta-das-eleicoes-2018-e-omedo/. (acessado em 14 de janeiro de 2019).

TODOROV, Tzvetan. 2010. O medo dos bárbaros: para além do choque das civilizações. Tradução de Guilherme João Freitas Teixeira. Petrópolis: Vozes.

TURBIANI, Renata. 2018. Eleições 2018: como se proteger da tristeza, da raiva e do medo?. In: https://www.bbc.com/portuguese/brasil-45772358 (acessado em 14 de janeiro de 2019).

ZOPPI-FONTANA, Mônica. 2011. "As imagens do invisível”. In: SARGENTINI, Vanice; PIOVEZANI, Carlos; CURCINO, Luzmara (org). Discurso, Semiologia e História. São Carlos, Claraluz, p.163-181. 